\title{
A New Perspective on Perspective Taking: A Multidimensional Approach to Conceptualizing an Aptitude
}

\section{Citation}

Gehlbach, Hunter. 2004. "A New Perspective on Perspective Taking: A Multidimensional Approach to Conceptualizing an Aptitude." Educational Psychology Review 16 (3) (September): 207-234. doi:10.1023/B:EDPR.0000034021.12899.11. http://dx.doi.org/10.1023/ B:EDPR.0000034021.12899.11.

\section{Published Version}

doi:10.1023/B:EDPR.0000034021.12899.11

\section{Permanent link}

http://nrs.harvard.edu/urn-3:HUL.InstRepos:11384950

\section{Terms of Use}

This article was downloaded from Harvard University's DASH repository, and is made available under the terms and conditions applicable to Other Posted Material, as set forth at http:// nrs.harvard.edu/urn-3:HUL.InstRepos:dash.current.terms-of-use\#LAA

\section{Share Your Story}

The Harvard community has made this article openly available.

Please share how this access benefits you. Submit a story.

Accessibility 
Running head: A NEW PERSPECTIVE ON PERSPECTIVE TAKING

A New Perspective on Perspective Taking:

A Multidimensional Approach to Conceptualizing an Aptitude

Hunter Gehlbach ${ }^{1}$

Submitted August 13, 2003

Revision submitted February 15, 2004

Mailing Address

Hunter Gehlbach

PO Box 13618

Stanford, CA 94309

(650) 967-4539

hgbach@stanford.edu

${ }^{1}$ Psychological Studies in Education Stanford University School of Education Stanford, CA 


\begin{abstract}
Social perspective taking (SPT) is thought to be important in its own right and is often associated with other important skills, such as interpersonal conflict resolution. Thus, it is critical for researchers to systematically understand SPT and how it relates to other valued educational outcomes. In particular, a complete understanding of SPT might assist educational psychologists to apply this knowledge in school settings to improve the effectiveness of students’ social interactions. Previous research on SPT, however, has conceptualized it as a unidimensional construct leaving scholars with an insufficient understanding of this aptitude. To best understand SPT, a multidimensional approach should include assessments of personal characteristics (including the propensity and the ability to engage in SPT) and features of the situation (including features of the SPT task and the larger context). Using Snow's conceptualization of aptitudes as a framework, this article illustrates the problems with treating SPT as a unidimensional construct, defines SPT as a complex aptitude, and provides a taxonomy to develop our understanding of SPT and to guide future research in this area. The taxonomy organizes and reviews the existing literature that relates personal and situational characteristics to SPT aptitude. Where research has not yet been conducted, this article hypothesizes how these characteristics will relate to SPT aptitude.
\end{abstract}

\title{
Keywords:
}

Perspective taking Conflict resolution Aptitude Adolescence Motivation 


\section{A New Perspective on Perspective Taking:}

A Multidimensional Approach to Conceptualizing an Aptitude

Submitted August 13, 2003

Revision submitted February 15, 2004

Yossarian: What would you do if you were me?

Chaplain: I don't know... I mean, I'm not you.

Yossarian: Imagine that you are me.

Chaplain: ...That's hard. Sometimes I even have trouble imagining that I'm me if you know what I mean.

-- (Henry, 1970, in the screenplay adaptation of Joseph Heller’s Catch-22)

The Chaplain's responses to Yossarian illustrate two important points about taking the perspective of somebody else. First, perspective taking is a challenging endeavor that requires cognitive ability. In this case, the Chaplain doubts he has sufficient ability. Second, the motivation, or propensity, to engage in perspective taking, is an equally important component of the process. For the duration of this interaction, the Chaplain never summons sufficient motivation to attempt taking Yossarian's perspective.

Understanding that perspective taking is more than a cognitive ability - that it also includes a motivational component - is crucial for educational psychologists. Being able to understand the perspective of another individual is critical for navigating most social situations. In addition to its intrinsic value, researchers have associated perspective taking with a host of other abilities and behaviors that are important to educators. For example, perspective taking is connected with developing historical understanding (Foster, 2001), fostering cooperation (Johnson, 1975), promoting moral reasoning and development (Hoffman, 2000), encouraging altruism (Batson, Early, \& Salvarani, 1995), reducing prejudice (Rokeach, 1960) and resolving conflicts (Deutsch, 1993). However, because empirical research on social perspective taking has often employed unidimensional measures of the construct, examining only the cognitive ability or the propensity to take perspective, scholars have struggled to clarify the link between perspective taking and these desired outcomes.

This article presents a multidimensional conceptualization of what is hereafter referred to as social perspective taking (SPT). This conceptualization should facilitate the study of SPT so that it can be understood and eventually taught in schools. In the first 
section, this article illustrates why unidimensional approaches are problematic for understanding SPT and how SPT relates to educational outcomes such as conflict resolution. The second section develops a more refined definition of SPT by borrowing from Snow's work to conceptualize SPT as a multidimensional aptitude (Corno et al., 2002; Snow, 1996). The third section uses this more comprehensive definition of SPT to present a taxonomy that organizes the previous research on SPT and offers a framework for future investigations. This taxonomy organizes personal factors (both cognitive and motivational) and situational factors (at the task level and features of the larger context) that relate to SPT.

\section{Unidimensional Approaches to Social Perspective Taking}

To understand the difficulties of treating SPT as a unidimensional concept, it is helpful to begin with a working definition. Johnson (1975) conceptualizes SPT as follows,

Taking the perspective of another person is the ability to understand how a situation appears to another person and how that person is reacting cognitively and emotionally to the situation. It is the ability to put oneself in the place of others and recognize that other individuals may have points of view different from one’s own (p. 241).

In other words, SPT consists of discerning what others are thinking and feeling in a nonegocentric manner. To make these discernments, one often needs to understand how others' perceive their situation ${ }^{2}$.

Defining SPT by considering it only as a skill, however, excludes important components of SPT. Most importantly, this definition does not address whether students are likely to engage in SPT in the first place (see Davis \& Franzoi, 1991). By adopting a unidimensional approach to studying SPT, scholars have limited their understanding of this aptitude and its relationship to interpersonal skills. A unidimensional approach

\footnotetext{
${ }^{2}$ Many authors use "empathy" to describe the same phenomenon of trying to understand the experience of others. This article uses the term "social perspective taking" because "empathy" often refers to empathetic distress, "an affective response more appropriate to another's situation than one’s own" (Hoffman, 2000 p.
} 
makes it difficult to know how the propensity or the ability to take perspective relate to effective social behavior. Are both aspects necessary for effective interpersonal interactions? Can strength in one area compensate for weakness in the other? Do these dimensions of SPT function additively or multiplicatively? In addition, unless features of the environment are also studied, little can be learned about how SPT aptitude varies across situations. Specifically, variations between those people whose perspective one attempts to take (i.e., SPT targets) and the broader context in which SPT occurs need to be studied. Thus, a multidimensional approach to studying SPT would ideally examine personal characteristics, including the propensity and ability to engage in SPT, and environmental characteristics, including features of the SPT task and the larger context.

Research relating SPT to conflict resolution illustrates how unidimensional approaches to SPT limit our understanding of the true relationship between the two. Perspective taking is often thought to be a critical component in conflict resolution and student mediation programs (Corcoran \& Mallinckrodt, 2000; Sandy \& Cochran, 2000). Due to episodes of school violence in recent years (e.g. the shootings in Littleton, CO; Santee, CA; and Erfurt, Germany), research in violence prevention and mediation has become an especially important area for educational and school psychologists. Yet, it remains difficult to prove that superior perspective takers are better able to resolve conflicts.

The studies that examine the intersection of SPT and conflict resolution have generally assessed SPT in two ways. One approach assesses participants' propensity to take the perspective of others (usually by asking participants to complete a self-report survey). The second approach measures SPT ability and usually requires participants to complete a task designed to measure their SPT accuracy. I describe an example of each type of study below.

\section{Propensity}

Before describing the studies that examine SPT propensity, it is important to clarify what is meant by this term. The propensity to take the perspective of others is

4). Unlike social perspective taking, Hoffman's notion of empathy does not include a cognitive component. 
equivalent to one's motivation to choose to take the perspective of others over many instances and situations; it is a general disposition towards taking the perspective of others. Thus, SPT propensity can be measured by assessing the frequency with which individuals attempt to take the perspective of others. For a single SPT opportunity, it is the probability that a perceiver will attempt to take the perspective of a target person or group.

In one approach that connects SPT to conflict resolution, researchers ask participants to self-report how frequently they are motivated to take the perspective of others. They correlate this self-assessment of SPT propensity with a measure of conflict resolution. One commonly used survey in this approach to perspective taking has been the seven-item subscale of Davis’ (1983) Interpersonal Reactivity Index entitled “Perspective Taking” $(\alpha>.70)$.

Although this approach has found positive correlations between SPT propensity and conflict resolution, this methodology leaves many unanswered questions about the true association between SPT and conflict resolution. For example, Corcoran and Mallinckrodt (2000) found moderate relationships between self-reported perspective taking propensity (using the Davis, 1983 scale) and the two mutually focused styles of conflict resolution (i.e., with the compromising, $r=.29$, and integration styles, $r=.39$, of conflict resolution). The authors note several potential biases associated with self-report measures in their discussion of limitations. However, even if the self-report biases were eliminated, there is an even more problematic issue: What if many of the high propensity perspective takers were inaccurate? If these frequent perspective takers habitually misread the thoughts and feelings of others, then they might not be adept at compromising or creating integrative resolutions to conflicts. Not knowing these participants SPT ability or the relationship between their SPT ability and SPT propensity makes these correlations difficult to interpret.

\section{Ability}

The second approach researchers have used to connect SPT to conflict resolution has focused on SPT as an ability. Researchers using this approach usually measure SPT ability by assessing how accurately a perceiver infers the thoughts or feelings of a target person. Ickes and his colleagues (Ickes, 1997; Ickes, Stinson, Bissonnette, \& Garcia, 
1990) have done much of the work on assessing people's ability to take the perspective of others. Their approach to measuring SPT accuracy has been to videotape two participants during an unstructured interaction. At the end of the interaction, the individuals retreat to separate rooms and watch the tape, reporting their own thoughts and feelings at certain instances during the interaction. Next, the participants watch the tape again and while trying to take the perspective of their conversation partner. The tape is paused at the same instances and they are asked to infer the thoughts or feelings of the other participant at that moment. The inferred thoughts and feelings are then compared to the self-reported thoughts and feelings and are coded for accuracy. Ickes et al. (1990) found that this method produced reliable assessments of accuracy $(\alpha=.91)$.

Studies adopting this approach to assessing SPT have also indicated a relationship between SPT and conflict resolution, but unanswered questions remain here too. For example, Bissonnette, Rusbult, and Kilpatrick (1997) related the SPT accuracy of newly married couples ( $\mathrm{N}=123$ pairs) to their scores on assessments of conflict resolution. They showed that higher accuracy scores were associated with the inhibition of behaviors that would escalate conflicts and with measures of how well the couple functioned. When they found consistent evidence for this relationship early in the study but not a year later, they concluded that motivational differences might have partially explained the results. Specifically, they suggested that as couples' marriages become more stable over time, their propensity to actively take one another's perspectives as a means to preempting potential conflicts may decline. The important point here is that without assessing SPT propensity, these results also leave the relationship between SPT and conflict resolution unclear.

In sum, SPT is thought to be a key component in important outcomes such as resolving conflicts. However, neither approach clarifies whether propensity and ability (1) allow people alternative pathways to successful conflict resolution, (2) are both necessary to resolve conflicts, or (3) interact to facilitate conflict resolution. Because SPT has usually been defined and studied as either a propensity or an ability, it is rare that measures of these constructs, such as frequency and accuracy, are collected in the same study. Thus, results illustrating relationships between the two are generally speculative and/or leave many questions unanswered. However, treating SPT as an 
aptitude could lead to a more thorough understanding of SPT that may help future researchers conceptualize and measure it. This understanding, in turn, may clarify how SPT relates to conflict resolution and other outcomes. This clarity would be particularly valuable for educators trying to develop more adaptive interpersonal skills, such as conflict resolution, in their students.

\section{Snow’s Situated Aptitude Theory}

The previous section identified and illustrated one way in which Johnson's (1975) formulation of SPT could be elaborated - namely his definition focused only one dimension of SPT (ability) and did not address the propensity to engage in SPT. Two additional criteria are also important to include in a comprehensive definition of SPT.

First, SPT is not only multidimensional in the sense that it must incorporate cognitive ability and propensity, but it also depends upon characteristics of the situation. Both SPT propensity and ability will depend on how the environment and the perspective taker influence each other. In other words, it is a construct that is situated. For example, a social studies student who is trying to better understand Napoleon's actions by taking his perspective will be impacted by a multitude of situational factors. Is she working under the pressure of a timed test, or is she just beginning a research project that is due in four weeks? Is her social studies class dynamic and interesting to her? Does the student view this exercise as relevant and important to her future? Each of these characteristics of the SPT task and the larger context could impact the student's propensity and ability to take Napoleon's perspective.

Second, as indicated in the discussion of the differences between SPT propensity and accuracy, it is clear that any definition of SPT should encompass a broad range of SPT outcomes. Specifically, for students attempting to take the perspective of others, four potential outcomes might result. They could: (1) accurately discern the cognitions and emotions of the others, (2) make inaccurate inferences, (3) conclude that they do not know what the others are thinking or feeling, or (4) disengage from the attempt. Here too, it appears that students' propensity to engage in SPT must be accounted for in addition to their actual ability in discerning the thoughts and emotions of others. For example, there may be some benefit to having students who frequently attempt to take the 
perspective of others, even if they conclude that they do not know how the others are thinking and feeling. By withholding judgment, or entertaining multiple potential explanations, they may have the chance to learn new information rather than leaping to erroneous conclusions. Attending to SPT propensity and accuracy in assessing the outcomes of SPT attempts can also clarify how SPT relates to other outcomes. For example, in some laboratory studies, students who are high in SPT accuracy but low in propensity might score well on conflict resolution measures (where the experimenter provides adequate motivation to engage in SPT). However, the same students may fare poorly in naturalistic studies of conflict resolution because they are never explicitly motivated to engage in SPT. In sum, a comprehensive definition of SPT needs to address the propensity to engage in SPT, the cognitive ability to do so, characteristics of the situation, what the outcomes of SPT attempts might be, and how these outcomes might impact other abilities such as conflict resolution.

Richard Snow’s conceptions of aptitudes (Corno et al., 2002; Snow, 1996) can be applied to SPT to address these issues. Three of Snow's propositions about aptitudes are particularly useful: his view that aptitudes are multidimensional, his notion that aptitudes interact with situations, which have multiple layers, and his focus on both the process and the product of aptitudes. Furthermore, Snow's (1996) conceptualization of aptitudes is particularly appropriate for educators. He views the primary function of schooling as the development of aptitudes. Thus, using Snow's conceptualization of aptitudes to define SPT may ultimately allow researchers and educators insights into the best ways to teach this aptitude.

\section{Aptitudes as multidimensional}

Snow defines aptitude as the "degree of readiness to learn and to perform well in a particular situation or in a fixed domain” (Corno et al., 2002, p. 3). According to Snow, Corno, and Jackson (1996), three facets of the mind play a role in aptitudes: cognition (e.g., being able to analyze and interpret events), affect (e.g., feelings and emotions), and conation (e.g., goal setting and will). Any aptitude such as perspective taking develops via two "pathways." In the "commitment pathway” parallel processes run concurrently. Individual students assemble their motivational resources, energizing their effort to work on and complete tasks. Meanwhile, affective and volitional resources within the 
commitment pathway modulate how the work proceeds. In the "performance pathway" students assemble and use cognitive resources to accomplish tasks in given situations. Effective coordination of these pathways in given situations results in successful performance. Over time, these pathways coalesce into an "aptitude complex.”

This conception of an aptitude complex is particularly useful for defining and studying SPT. The “commitment” resources, such as motivation and emotion regulation, that students assemble determine their SPT propensity. In other words, the propensity to engage in SPT is the main outcome of the commitment pathway; it can be assessed by measures of how frequently students engage in SPT. Meanwhile, the assembly of students’ cognitive resources (including their abilities to comprehend others’ words and gestures, strategies for taking perspective, and style of processing i.e., holistic or individualistic) determines their SPT ability. That is, students' SPT ability is a direct result of their performance pathways, which can be assessed by measuring how accurately they take the perspective of others.

\section{Layers of the Environment}

Understanding SPT also requires understanding the nature of SPT tasks and the environment in which those tasks are situated. Snow (1994) viewed students as engaging an aptitude within a "problem space.” The problem space includes the specific task and the larger situation in which the task is embedded ${ }^{3}$. Both the task and the larger context offer constraints and affordances to students working within the problem space. In other words, students engage aptitudes on specific tasks in settings whose characteristics impact which cognitive and motivational resources are assembled to address the task in that setting. However, what is more important than the actual constraints and affordances of the situation, according to Snow, is the student's perception of the environment (Corno et al., 2002). Each time a student acts on the problem space, the environment changes. With each change, new constraints and affordances emerge. A modified perception of that problem space will likely result, and this perception may impact the student's future

\footnotetext{
${ }^{3}$ Snow's conception of the environment also includes the idea of a "treatment" i.e., tasks are embedded within treatment groups that exist within contexts. Because SPT is rarely taught in schools, the notion of a treatment or teaching effect seemed unnecessary in describing SPT. Consequently, this article divides the situation into task-level and contextual-level factors only.
} 
actions. In this manner, students' aptitude complexes interact with both the task and the larger situation.

To give an example for a perspective-taking task, suppose a group of students passes their teacher in the hallway and tries to get a sense of their teacher's thoughts and feelings. Two layers of the situation are important: characteristics of the task (in this case, their strict and serious English teacher is the perspective taking task or target), and the environment in which the task is situated (i.e., the hallway). As soon as the students or the teacher act in the problem space (perhaps the teacher breaks into a wide smile and greets the students warmly), the environment and, more importantly, the students' perceptions of the environment have changed. This may cause them to recalibrate their perception of their “strict” English teacher and infer that the teacher's thoughts and feelings differ substantially between classroom and non-classroom settings.

\section{Aptitudes as Processes and Products}

Snow emphasized that aptitudes such as intelligence are the, "raw material for education and a product of education” (Martinez, 2000, p. 127). In other words, aptitudes such as intelligence or perspective taking, needed to be studied as inputs and as outcomes. This dual emphasis seems particularly important for investigations of social perspective taking. It is important to study social perspective taking as process that facilitates other outcomes such as conflict resolution skills. However, it is equally important to study SPT as a product. If scholars are to develop a sufficient understanding of this aptitude so that it can be taught to students, they need to understand how a broad range of personal and situational characteristics impact SPT ability and propensity.

In sum, students' SPT aptitude depends upon how effectively their cognitive and motivational resources (i.e., their performance and commitment pathways) interface with SPT tasks that are situated within a broader educational context. Aptitudes may be important in their own right (e.g., SPT as a form of interpersonal understanding) and may also be important as a means to another end (e.g., SPT as facilitating conflict resolution). Figure 1 provides a visual synthesis of how Snow's ideas apply to a SPT instance. The figure illustrates that students assemble both cognitive and motivational resources as they attempt a perspective-taking task such as discerning the thoughts and emotions of their 
teacher. They perceive constraints and affordances within the task (e.g., some teachers might display their emotions more readily than others) and the context in which the SPT task is situated (e.g., teachers may try to maintain a more professional appearance in the classroom as compared to the supermarket). As the students interact with the SPT task over time (e.g., by greeting their teacher), their perceptions of their teacher and the context may change.

\{Insert Figure 1 about here

\section{Dimensions of Social Perspective Taking}

Snow's ideas indicate that the study of SPT should examine the performance and commitment pathways and how these pathways interact with situational characteristics at the level of the task and of the larger context. As mentioned previously, most past research on SPT focused on only one of the interpersonal dimensions: SPT propensity (as a commitment outcome) or SPT ability (as a performance outcome). Although it appears to be critical to assess both dimensions simultaneously, much can be learned by reviewing past studies even if they focus only on one dimension of SPT. In addition, these studies can provide the bases for hypothesizing how personal and situational characteristics that seem logically connected to SPT (but that have not been studied explicitly) might relate to the outcomes of propensity and accuracy.

This section reviews studies that have related personal and situational characteristics to SPT propensity and ability and hypothesizes relationships for those characteristics that have not yet been investigated. The goal of this section is not to provide an exhaustive description of these studies, but rather to show how the personal and situational characteristics thought to be associated with SPT fit within the framework of an aptitude complex. These characteristics are organized into a taxonomy that is summarized in Tables 1 and 2. The taxonomy is structured so that, as one moves from left to right, perspective taking should be facilitated by increasing propensity and/or accuracy. 


\section{Person-Level Factors}

The commitment pathway

Motivation. The first major component of the commitment pathway is motivation. Motivation may be particularly influential on both the ability and propensity to take the perspective of others. For example, a student might be completely uninvested in trying to understand why Neville Chamberlain agreed to speak with Hitler. Yet, the same student may be highly invested in ascertaining why her significant other will not speak to her. There are likely to be substantial differences in the extent to which a student engages in the perspective taking process in these two situations. As a consequence of these different degrees of engagement the resultant accuracy of these attempts may differ.

Motivation and SPT propensity should be highly, positively related. The more motivated that students are to take perspective in any one instance, the more often they are likely to engage in SPT across many instances. Eccles (1984) showed that motivation (conceived of as a combination of one's valuing of a domain and expectancies to succeed within that domain) predicts choice in future activities. She examined academic achievement motivation as it related to choosing of future courses. However, there is every reason to think that those students who value SPT and think that they can be successful at it are the same students who should engage in SPT attempts more frequently. However, nobody has found clear evidence of this connection yet.

Unlike the motivation-SPT propensity association, there is empirical evidence for a connection between motivation and SPT ability. Most would guess that being motivated to take the perspective of others facilitates accuracy. There is, in fact, evidence supporting this notion. In one study Ickes et al. (1990) found that the perceiver's interest in the target person generally (and specifically in the target's attractiveness) positively influenced SPT accuracy. Using the video-tape procedure described earlier they found that the male participants tended to be more motivated to figure out the thoughts and feelings of the attractive female SPT targets. On the other hand, Simpson, Ickes, and Blackstone (1995) found that partners in close relationships may occasionally be motivated to be inaccurate in their perspective taking in order to cope with external threats to their relationship. They showed that some goals, such as 
maintaining relationship could supercede the goal of accurately identifying the thoughts and feelings of others. Thus, although motivation seems likely to increase SPT accuracy in general, exceptions may occur.

Emotion regulation. Emotion regulation is a second key component within the commitment pathway. Perspective taking, particularly in situations of conflict, will often involve emotionally charged situations; those individuals who successfully regulate their emotions are more likely to make attempts to take the perspective of others and are more likely to be accurate in those attempts. Specifically, those who can regulate their emotions effectively may minimize negative emotions that might interfere with cognitive processes or motivation.

Although little research has linked emotion regulation (or the resultant emotions) to SPT, some scholars have theorized that an important connection exists. For example, Mendoza (1997) describes how emotional factors may impact SPT propensity. He states that general fears of feeling weak or powerless may cause us to think that, "We will lose our 'emotional bargaining chips’ in a conflict if we empathize prematurely” (p. 48). Conversely, we may make more attempts to engage in SPT if we care about the other party or if we think that doing so might be a means to regulating our own anger. In sum, emotion regulation is likely to increase the propensity for engaging in perspective taking to the extent that students are successful in regulating their emotions to states that are conducive to perspective taking. Which emotional states are most conducive to engaging in SPT frequently is an important topic for future research.

Although there is no direct evidence linking emotion regulation to SPT accuracy, there is evidence from other domains that cognitive functioning may improve or decline depending upon one's emotional state. Roeser, Eccles, and Strobel (1998) found that negative emotions can potentially cause difficulties in academic achievement. Thus, future studies examining emotion regulation and SPT ability may find that those students who regulate their emotions effectively are more accurate in their SPT attempts. However, it is also plausible that those students who naturally tend towards certain emotional states (without having to actively regulate their emotions) may be most accurate. 


\section{Cognition: The performance pathway}

Cognitive level. Within the performance pathway, nobody has examined the relationship between cognitive level or intelligence and the propensity to take perspective. However, many scholars have sought to connect intelligence with SPT ability. There is reason to think that students' level of an intelligence such as verbal ability should relate to SPT ability. To accurately take the perspective of another, it is usually critical to understand what they are saying and what connotations their words have. However, there is no clear theoretical reason to think that verbal ability or another type of intelligence would necessarily be related to the propensity to engage in SPT.

Perhaps because there is no strong theoretical link between cognitive level and the propensity to engage in SPT, no studies have examined this possibility. It is possible that those students with a high propensity for taking the perspective of others might increase their intelligence more than their peers with a low SPT propensity. Perhaps they seek out and learn from multiple points of view on different issues, which helps them achieve a richer understanding of these issues. However, it seems equally plausible that intelligence and propensity to engage in SPT are unrelated. Thus, the nature of the relationship between cognitive level and SPT propensity remains an open empirical question.

On the other hand, the existing research does demonstrate a relationship between intelligence and SPT ability. Depending upon the measure of intelligence that is selected, the strength of the relationship between intelligence and SPT varies. Davis and Kraus's (1997) meta-analysis showed that intellectual functioning (as assessed by a variety of intelligence measures) is positively associated with social perspective taking accuracy at a modest level $(r=.23)$. Selman (1980) found that IQ correlated much more strongly with his five stages of perspective taking $(r=.77)$. Although cognitive level and SPT are clearly related, it is less clear why the degree of the association varies so much. If verbal ability (which Gustafsson, 1984, has shown to correlate highly with most forms of intelligence) is the primary cause of this association, the variation in the strength of these correlations may result from using intelligence tests or assessments of SPT that rely more or less on verbal ability. 
Strategy. The strategies people choose when taking perspective are also likely to impact SPT aptitude. These strategies vary in their effectiveness (particularly depending upon the situation). For example, a student who employs a strategy of imagining what she would do in the same situation might be very accurate if she uses this strategy with similar peers. Conversely, a teacher who attempts to discern his students' thoughts and feelings by assuming that all students are irritable and bored when in school might be particularly inaccurate.

Most of the impact of people's choices of strategies should be manifested in SPT ability. However, people's strategy selection may relate to SPT propensity - as people discover strategies that are successful and/or easy to implement, they may begin to use them more frequently. Alternatively, if people are encouraged to use difficult or ineffective strategies it may diminish their enthusiasm for perspective taking and reduce the frequency with which they attempt to figure out the thoughts and feelings of others. Although no research has been done on this particular association, the hypothesis is that effective strategies will relate positively to SPT propensity.

In general, as students learn to implement more effective strategies, their SPT ability should increase. Mendoza (1997) and Galinsky and Moskowitz (2000) found support for this idea. These researchers assigned students to different induction conditions (i.e., they told participants to use different SPT strategies) when instructing subjects to take another's perspective. In both studies the type of induction impacted the subjects' outcomes. In Mendoza’s (1997) study he compared a situation-based perspective-taking induction with an emotion-based induction. In other words, he instructed certain participants to imagine the other person's situation and others to imagine how the other person is feeling. In his first two experiments (dealing with increasing understanding between emotionally close partners), the emotion-based inductions were more effective for increasing perspective taking-accuracy. For his second two experiments (dealing with empathy towards transgressors), the pattern of results was less clear.

Galinsky and Moskowitz's (2000) divided participants into an in-group and an out-group based on their supposed tendencies to over- or under-estimate dots on a computer screen. They induced participants to write a short essay that did one of the 
following: (a) described a day in the life of an out-group member from the out-group member's perspective, (b) described ways in which the in-group and out-group members were similar, or (c) described a time when the participant behaved similarly to an outgroup member. They found that the first of these manipulations was the most effective for reducing the favoritism of the in-group over the out-group. While there is no clear consensus as to which SPT strategies lead to the most accurate perspective taking, it is clear that this is a fertile area for further exploration.

Cognitive style. It is difficult to assess how cognitive style might relate to SPT aptitude largely because of the difficulty in clarifying what cognitive style is. Davis and Kraus (1997) define it broadly as, "the way the individual thinks about the world" (p. 150). They used measures of tests of cognitive complexity, locus of control scales, field independence, and dogmatism scales as different measures of cognitive style. In addition to these cognitive styles, other scholars have hypothesized that individuals who process events in a more relational, holistic fashion may do a better job of attending to situational characteristics and, consequently, may be more frequent (and accurate) perspective takers.

Researchers studying gender have argued that certain cognitive styles, such as holistic processing, may be connected to SPT propensity. Graham and Ickes' (1997) posit that females are socialized to see the world in a more relational or holistic manner. According to these scholars, because of this focus on relationships and the functioning of whole systems (as opposed to a focus on individuals), females may tend to engage in SPT more often. Cross-cultural research provides another illustration of how cognitive style may impact SPT propensity. Morris and Peng (1994), showed that Asians have developed a cognitive tendency to focus on the field or the situation as a whole (i.e., holistic style) to a greater extent than European-Americans who focus more on the actors within a situation (i.e., dispositional style). Because these two examples confound gender or culture with cognitive style, it is not clear whether these differences in SPT propensity are the result of differences in cognitive style. However, future studies relating cognitive style to SPT propensity while controlling for gender and ethnicity should clarify this question. 
In relating cognitive style to SPT ability, Davis and Kraus (1997) used a metaanalytic approach. They found an average effect size of .16 for the relationship of cognitive style to perspective taking accuracy. The effect sizes varied from .27 to .08 depending upon how cognitive style was assessed. Thus, there does appear to be a weak relationship between cognitive style and SPT ability, however this relationship depends in large part on the type of cognitive style being considered.

Although cognitive style (particularly the dispositional versus holistic styles) may have a relatively straightforward impact on SPT propensity, it may have a curvilinear relationship with accuracy. Up to a point, it would seem that holistic processors who tend to focus more on the situations of others are likely to do a better job of social perspective taking. However, if a perspective taker focuses solely on the situation and never considers the person, accuracy may decrease.

To summarize, people's perspective-taking aptitude should depend in part on their commitment to trying to ascertain the thoughts and feelings of a particular target - how motivated they are, and how well they regulate their emotions. SPT aptitude will also depend upon the cognitive resources that individuals assemble to perform the attempt what their cognitive ability is within this domain, what strategies they select, and what cognitive style they bring to the situation.

\{Insert Table 2 about here\}

\section{Situation-Level Factors}

The second half of the taxonomy describes the features of the perspective-taking situation - both the task and the broader context in which the task takes place (see Snow, 1994). A social perspective-taking task is any episode in which an individual attempts to take the perspective of somebody (a target person or group of people) in some context. Students' SPT propensity and accuracy will vary according to seven aspects of these tasks: locus, decipherability, familiarity, temporality, reality, duration, and morality. Two features of the broader context, cooperativeness and distractions, are also likely to be important. See Table 2. 


\section{Task Features}

Locus. The first feature of the perspective taking task that is likely to impact SPT propensity and accuracy is the locus of the perspective being taken. In the same way that English grammar distinguishes between "I,” “you,” and "he/she/it,” the perspective being taken in any given task varies by person. In other words, people can take their own perspective, put themselves in the shoes of another actor, or attempt to be a thirdperson/neutral observer. The singular versus plural aspect of the grammatical analogy distinguishes between those instances when students take the perspective of an individual (a specific teacher) or a group (ninth graders). In some instances, people’s perspectives as individuals may contradict their perspectives as a group member. For example, the personal beliefs of Democrats and Republicans in the United States do not always align with their party's platform.

Not shifting from one's own perspective (e.g., trying to assess what you might think or feel in a hypothetical situation) is probably cognitively less demanding than actively taking another's perspective. Fiske and Taylors' posit that people are “cognitive misers” and minimize the amount of cognitive effort that they exert (see Fiske, 1995). If they are correct, people should default to taking only their own perspective. To do otherwise would be an expenditure of cognitive resources. Thus, students' are hypothesized to engage in SPT least frequently when taking the perspective of others, more often for taking a neutral perspective, and highest for taking their own perspective.

Social psychology has repeatedly demonstrated how people’s SPT ability is susceptible to errors when they shift from taking their own perspective to taking the perspective of others. In one famous experiment, Jones and Nisbett (1971) showed how people (mis)understand each other depending upon whether they are functioning as an actor or an observer. In their experiment, actors made attributions to the environment while observers made dispositional attributions to the actor. Ross, Amabile, and Steinmetz (1977) extended this work with a “Quiz Show” study. Undergraduate observers made attributions of higher intelligence to a questioner than to the answerer even though the situation overwhelmingly favored the question asker. Ross and Nisbett (1991) summarized much of this work as a phenomenon Ross called the "fundamental attribution error,” i.e. the tendency to routinely underestimate the power of situational 
influences. The fundamental attribution error can also be viewed as an inability for observers to successfully "put themselves in the shoes of actors.” Although these studies do not assess SPT ability directly, they provide compelling evidence that the observers in these types of studies are prone inaccurate perspective taking because they do not adequately understand the situation when shifting from their own perspective to the perspective of the actor.

Decipherability. A second important feature of any perspective-taking task is the ease with which the target person can be deciphered. Trying to take the perspective of certain individuals who may show little emotion, offer few words, or disclose minimal information through body language is likely to be harder than taking the perspective of a highly expressive individual. Similarly, somebody whose mood fluctuates rapidly or who actively tries to deceive others (perhaps by pretending they are in a good mood) will make for a more difficult perspective-taking target. The target person's expressiveness, the stability of their mood, and their level of deception may impact SPT propensity and ability.

In general, there is no clear hypothesis as to how decipherability will affect SPT propensities. A challenging SPT target may inspire some to engage in SPT while deterring others. However, when the perspective taker realizes that attempts at deception are being made, the student may become more curious as to the motivation that underlies the deception. In this situation, perspective taking attempts would likely increase.

There is little research that varies the decipherability of the target and examines its impact on SPT ability. Oswald (2002) did vary the affective demeanor and the cognitive content of the target in her study on perspective taking. However, she examined helping behavior as an outcome rather than SPT accuracy. In one of the few examples of research that investigated accuracy and characteristics of targets, Bernstein and Davis (1982) found that highly self-conscious targets were easier perspective taking targets than minimally self-conscious targets in a study where subjects had to match individuals seen in a video to their self-descriptions. However, the authors noted that this result may stem from highly self-conscious targets producing more accurate selfdescriptions. 
In his work on facial expressions of emotion, Ekman (1993) describes several ways in which people attempt to deceive others who might be trying to read how they are feeling. Often people use false expressions so that perceivers do not know (and perhaps will not inquire about) certain moods. In other instances, targets may deceive potential perspective takers by following “display rules” - cultural norms regarding which emotions are appropriate to express at certain times. Finally, people often use referential expressions of emotion. Although these are not intended to deceive according to Ekman, the intent to communicate an emotion that is not being felt (e.g., a forced smile at a joke that is clearly not funny) could be confused. In each of these cases, a deceptive target should be harder to decipher and therefore should reduce SPT accuracy.

Familiarity. Some SPT targets, such as family and friends, are likely to be familiar to the perspective taker while others will be novel. The degree to which a perspective taker is familiar with a target person is another feature of the SPT task that may affect the perspective taker's propensity and ability. There is some direct evidence of this connection, although most of the empirical support comes indirectly from a branch of social psychology focused on prejudice and in-group/out-group paradigms .

Almost necessarily, students will take the perspective of those with whom they are more familiar and interact with regularly more often than with strangers. For example, students will more frequently try to take the perspective of their best friend or of a family member than of a teacher they have not had yet. They simply have more social contact with their friends and family and therefore have more opportunities for SPT. Perhaps because this hypothesized association seems obvious, no research has examined this relationship explicitly. Thus, empirical confirmation of this assertion would be helpful.

Some empirical work has connected familiarity and SPT accuracy. Colvin, Vogt, and Ickes (1997) review much of this work. However, Stinson and Ickes (1992) provide the most direct empirical support of this connection. By using their procedure of videotaping unstructured interactions (see Ickes et al., 1990), they found that male friends were more accurate in reading each other's thoughts and feelings than male strangers. Though it would be helpful to see this result generalized beyond male college students, there is no reason to suspect that the results should differ for other populations. 
Social psychologists studying prejudice provide compelling theories that help explain this connection. Allport's (1954) The Nature of Prejudice explains the human tendencies of categorizing and taking mental shortcuts as natural and common - he even dedicates a chapter to “The normality of prejudgment.” Years later, Fiske and Taylor helped explain this phenomenon by describing people as "cognitive misers" to indicate that people tend to conserve cognitive effort by using categories rather than processing all stimuli individually (see Fiske, 1995). Devine’s (1995) summary of this work illustrates why people's tendencies to be cognitive misers is important to the study of perspective taking. First, as Allport indicated, categorization is normal and even necessary for proper functioning. Second, there is an "out-group homogeneity effect." In other words, we tend to see all the members of an out-group as alike, whereas we can see members of our in-group more as individuals. Third, Devine cites research from Brewer (1979) and Rosenbaum and Holtz (1985) as indicating that, "Mere categorization of people into groups is sufficient to increase attraction to in-group members and may at times lead to a devaluation of out-group members” (p. 469). In sum, if we categorize as a regular cognitive function, view out-groups as homogeneous, and then favor our in-group over the out-group, it becomes clear that we are going to do a poor job of taking the perspective of out-groups with whom we are less familiar.

Temporality. The next feature of SPT tasks that may impact both SPT propensity and accuracy is temporality - some tasks require taking perspective of a past event, some a present event, and some a future event. No research specifically manipulates this element of a perspective-taking task to examine its impact on SPT propensity or accuracy. Yet this task feature does appear to be an important issue for students. In their examination of risk and resiliency in adolescence, O'Donoghue and Rabin (2000) address this issue of temporality specifically by noting that youth do not always effectively foresee the future ramifications of their present actions.

In spite of the absence of empirical support, it seems reasonable to assume that SPT propensity should also be highest in the present. The SPT targets that are likely to be most salient to students are those in their present environment. Furthermore, it is most pressing for students to interact effectively with those who are in students' present environment (creating an additional motivation for students to engage in perspective 
taking). The propensity to try and take perspective of others might be equally high in the future as in the past. For example, it is hard to know whether students will more frequently try to figure out "Was my friend upset by my actions?" or "Will my friend be upset if I take a certain action?”

Similarly, one would hypothesize that SPT ability should be highest in the present. SPT accuracy should be highest in the present because people will usually have the most information about others and about situational clues in the present. Generally, students will have more information about past events (because they can be experienced or recorded) than future events. Thus, one would also hypothesize that SPT should be more accurate for SPT attempts that reflect upon past situations than for attempts that try to anticipate future situations.

Reality. Tasks requiring perspective taking can exist in reality or be hypothetical. Whether a given task is purely hypothetical, is likely to occur, or really exists, may impact the perspective taker's propensity and ability. Although no research has explicitly compared hypothetical and real perspective taking targets, past research has used both approaches. For example, Selman’s (1980) approach to assessing perspective taking was to read hypothetical scenarios to students and ask them to infer how different characters in the scenarios were thinking and feeling. Conversely, Ickes and his colleagues (see Ickes, 1997) used a laboratory technique (described earlier in the “Ability” subsection) that requires participants to actually decipher the thoughts and feelings of other participants who they meet and interact with.

One would hypothesize that students’ SPT propensity would be higher in real situations. Presumably, students feel a greater press to take the perspective of those who they are having real social exchanges with in their daily lives. The behaviors of real perspective taking targets are most likely to directly influence students. Although there may be substantial thought given to hypothetical SPT tasks (e.g., when deciding whether or not to do their homework, students may try to imagine what the teacher will think if they do not submit it), it seems unlikely that students will engage in these instances as often as they engage in perspective taking for real SPT tasks.

For reasons similar to those given in the "Temporality" section, one would hypothesize that students should be more accurate in their SPT attempts for real tasks 
than for hypothetical ones. Specifically, there will be many more informational cues to guide students in taking the perspective of real people in real contexts than in hypothetical situations.

Duration. Another feature of the task that is likely to impact students' SPT aptitude is the duration that they are exposed to perspective taking targets. This characteristic does not apply to SPT propensity because the duration of exposure time assumes that people are already engaged in SPT attempts.

However, longer exposure to a SPT target should help perspective takers become more accurate in two ways. First, the more time people practice their SPT skills, the better they are likely to become. Although there is no direct evidence for this conjecture, perhaps one reason that many developmental scholars (e.g., Eisenberg, Murphy, \& Shepard, 1997; Selman, 1980) have found positive correlations between age and SPT ability is that older students have had more SPT practice. In other words, those with more life experience have amassed more total practice time to develop their SPT ability.

Second, within a single SPT attempt, the longer a person can focus on a particular target and learn about his or her habits, background, and personality, the more likely the person is to draw accurate inferences about the target's affective or cognitive state.

Bernstein and Davis (1982) found a trend in this direction using a video-tape procedure to assess SPT ability. When perspective takers viewed a longer tape (about 7:30 minutes) they tended to be more accurate than when viewing a shorter tape (about 4:00 minutes), although their results did not achieve statistical significance $(p<.20)$. Longer differences in duration may show greater mean differences in future studies.

Morality. Perspective taking tasks will vary in the extent to which they include a moral dimension. Although this variation is unlikely to impact students' SPT propensity, it will likely affect their SPT accuracy. Selman (1976) clarifies the relationship between morality and perspective taking, "Moral judgment considers how people should think and act with regard to each other, while social role taking considers how and why people do in fact think about and act toward each other” (p. 307). Some perspective taking tasks involve evaluating people in relation to social conventions (see Nucci, 1989), some in relation to moral judgments, and some involve neither. Kohlberg's (1994) research on moral reasoning illustrates one end of this continuum. Participants in his research were 
interviewed and asked to figure out what an actor in a moral dilemma should do. In the process of responding to the interviewer, participants were implicitly encouraged to take the perspective of the characters in the scenarios and/or a third-party perspective. Other studies, such as Taylor and Fiske (1975), ask participants to take the perspective of others without any moral component to these perspective-taking tasks.

Morality seems unlikely to impact SPT propensity directly. However, the extent to which a SPT task has a moral dimension is likely to impact SPT ability. A moral SPT task has an extra layer of cognitive complexity and should be more difficult than a nonmoral task. For example, if a student were asked to take the perspective of a boy who is contemplating buying a candy bar, the boy's thoughts and emotions are likely to be relatively straightforward, “Can I afford this candy bar? How hungry am I?” Yet, if he were contemplating stealing the candy bar, it may become more difficult to take his perspective. In addition to the earlier questions, one might guess that the boy could feel angry, ashamed, or energized and the number of thoughts going through his head could be much more numerous (e.g., Can I get away with it? What would happen if I get caught? Is it worth the risk? What will my friends think?). Although empirical confirmation is needed, moral perspective taking tasks are expected to be more difficult and, therefore, reduce SPT accuracy.

\section{Context}

Cooperativeness. The broader context that a SPT task is situated within is also likely to impact SPT aptitude. One such feature of the broader context that is likely to impact SPT propensity and ability is the cooperativeness of the climate that the task takes place in.

Theorists such as Deutsch (2000), who are interested in the intersection of SPT and conflict resolution, have viewed the framing of the situation (as cooperative rather than competitive) as paramount to successful conflict resolution. Many of the norms that he lists for cooperative interactions involve perspective taking. For example, he advises, "When there is disagreement, seek to understand the other's views from his or her perspective; try to feel what it would be like if you were on the other's side” (p. 32). Elsewhere, Deutsch (1993) implies that the more often SPT occurs, the more that a situation is likely to be perceived as cooperative (as opposed to competitive). Whether 
this hypothesized association works in the reverse (cooperative settings facilitating more SPT), remains an open question.

In connecting cooperation with SPT ability, Johnson (1975) linked SPT ability and fourth graders' predisposition to cooperate. He found that their emotional perspective ability was positively associated with their level of cooperation. Johnson's (1975) work focuses on competition or cooperation as an individual characteristic. However, these results indicate that students' who are more likely to foster a cooperative climate are those who are more likely to be accurate perspective takers. Thus, one would hypothesize that a more cooperative climate should be associated with SPT ability, although the direction of causality is not necessarily clear.

Distractors. Distractions that exist in the environment in which a SPT task is set are likely to impact both SPT propensity and ability. Scholars have not directly examined whether more distracting environments reduce students' SPT propensity and ability. However, evidence indicates that distractions that are present in the environment while a perspective-taking task is attempted will likely pull cognitive resources away from the perspective-taking attempt. This reduction of cognitive resources is likely to lower both SPT propensity and ability. As the environment presents more stimuli to focus on, students have less attention to direct to a perspective-taking target and are less likely to engage in a specific SPT attempt as a result. In the same way that cognitive load has been shown to increase difficulty for various types of cognitive tasks (Wegner, 1994), one would predict that as distractors accumulate in a situation, a person's cognitive load will increase and their SPT accuracy will decline. Hodges and Wegner (1997) explain that, "When we are actively trying to take another's perspective, mental loads can lead us to be particularly cruel to that person” (p. 329).

In sum, students' SPT aptitudes interface with the characteristics of specific perspective taking tasks. These characteristics include locus, decipherability, familiarity, temporality, reality, duration, and morality. SPT aptitudes are also influenced by qualities of the environments in which the SPT tasks are situated. These environmental characteristics include cooperativeness and distractors. 
A final note warrants mention, Snow's theory included an additional component that is also relevant to SPT. Snow and Yalow (1982) felt that understanding an aptitude complex included understanding interactions within the aptitude complex and between the aptitude complex and characteristics of the environment. In other words, components of the commitment pathway are likely to interact with components of the performance pathway. Those components may also interact with features of the SPT task and the environment containing the SPT task. Because the taxonomy presented here relies heavily on indirect evidence and conjectures, to speculate further about which factors might interact seemed premature. Thus, these were not included in the taxonomy.

However, because interactions played such an important role in Snow's thinking, it is helpful to provide one illustration of the type of interaction that is likely to occur within the taxonomy. The temporality dimension of the SPT task is likely to interact with students' capacity to regulate their emotions, which will likely impact SPT ability. For SPT tasks of relatively low emotional investment, more recent events should be more easily remembered. Thus, SPT ability should be relatively high. On the other hand, for a difficult interpersonal conflict, one would predict that, if the perspective taker is particularly upset, accuracy in seeing the other person's perspective might suffer. In this case, more temporal distance from the event would foster more accurate perspective taking. Hopefully, as more empirical evidence is accumulated within the framework of the taxonomy, scholars can begin looking at some of these interactions.

\section{Summary}

Drolet, Larrick, and Morris claim that, “A common, almost proverbial, belief in our culture is that unnecessary conflicts could be resolved if only individuals would consider the needs and wants of their opponent” (1998, p. 25). Social perspective taking is a complex aptitude that may impact conflict resolution and many other skills that educators would like to develop in their students. However, too little is known about how perspective taking functions for researchers clarify how SPT relates to these skills or how it might best be taught to students.

This article argues that much of this lack of knowledge of perspective taking is due to insightful, yet insufficient studies that examined only one dimension of SPT: either SPT propensity or SPT accuracy. Without an understanding of both the cognitive, 
motivational (i.e. performance and commitment pathways), and situational factors that impact SPT, educational psychologists are unlikely to develop their understanding of SPT. Because understanding the thoughts and feelings of others is imperative for navigating social situations and relates to other valued outcomes such as conflict resolution, developing a clear understanding of this aptitude so that we might teach it effectively seems particularly important.

This article presented a framework that can help organize research on SPT so that educational psychologists can systematically explore this aptitude and fill in current gaps in knowledge. The taxonomy illustrating the major factors in SPT may change as new empirical evidence emerges. However, without a common starting point, research efforts in this area are likely to be uncoordinated and unproductive.

As the opening dialogue between Yossarian and the Chaplain indicated, social perspective taking is complex and challenging. A more complex, multidimensional approach to assessment of this aptitude is needed better understand it and to shed light on its relationship with important outcomes such as conflict resolution. 


\section{References}

Allport, G. W. (1954). The nature of prejudice. Cambridge, MA: Addison-Wesley. Batson, C. D., Early, S., \& Salvarani, G. (1995). Immorality from empathy-induced altruism: When compassion and justice conflict. Journal of Personality and Social Psychology, 68(6), 1042-1054.

Bernstein, W. M., \& Davis, M. H. (1982). Perspective-taking, self-consciousness, and accuracy in person perception. Basic and Applied Social Psychology, 3(1), 1-19.

Bissonnette, V. L., Rusbult, C. E., \& Kilpatrick, S. D. (1997). Empathic accuracy and marital conflict resolution. In W. J. Ickes (Ed.), Empathic accuracy (pp. 251-281). New York, NY, US: Guilford Press.

Brewer, M. B. (1979). In-group bias in the minimal intergroup situation: A cognitivemotivational analysis. Psychological Bulletin, 86, 307-324.

Colvin, C. R., Vogt, D., \& Ickes, W. J. (1997). Why do friends understand each other better than strangers do? In W. J. Ickes (Ed.), Empathic accuracy (pp. 169-193). New York: The Guilford Press.

Corcoran, K. O., \& Mallinckrodt, B. (2000). Adult attachment, self-efficacy, perspective taking, and conflict resolution. Journal of Counseling \& Development, 78(4), 473483.

Corno, L., Cronbach, L. J., Kupermintz, H., Lohman, D. F., Mandinach, E. B., Porteus, A. W., et al. (2002). Remaking the concept of aptitude: Extending the legacy of Richard E. Snow. Mahwah, NJ: Lawrence Erlbaum Associates.

Davis, M. H. (1983). Measuring individual differences in empathy: Evidence for a multidimensional approach. Journal of Personality and Social Psychology, 44(1), 113-126.

Davis, M. H., \& Franzoi, S. L. (1991). Stability and change in adolescent selfconsciousness and empathy. Journal of Research in Personality, 25(1), 70-87.

Davis, M. H., \& Kraus, L. A. (1997). Personality and empathtic accuracy. In W. J. Ickes (Ed.), Empathic accuracy (pp. 144-168). New York: The Guilford Press.

Deutsch, M. (1993). Educating for a peaceful world. American Psychologist, 48(5), 510517. 
Deutsch, M. (2000). Cooperation and competition. In M. Deutsch \& P. T. Coleman (Eds.), The handbook of conflict resolution: Theory and practice (1st ed., pp. 2140). San Francisco: Jossey-Bass.

Devine, P. (1995). Prejudice and out-group perception. In A. Tesser (Ed.), Advanced social psychology (pp. 466-524). New York: McGraw-Hill.

Drolet, A., Larrick, R., \& Morris, M. W. (1998). Thinking of others: How perspective taking changes negotiators' aspirations and fairness perceptions as a function of negotiator relationships. Basic \& Applied Social Psychology, 20(1), 23-31.

Eccles, J. (1984). Sex differences in achievement patterns. In T. B. Sonderegger (Ed.), Nebraska Symposium on Motivation (Vol. 32, pp. 97-132). Lincoln, NE: University of Nebraska Press.

Eisenberg, N., Murphy, B. C., \& Shepard, S. (1997). The development of empathic accuracy. In W. J. Ickes (Ed.), Empathic accuracy. (pp. 73-116). New York: The Guilford Press.

Ekman, P. (1993). Facial expression and emotion. American Psychologist, 48(4), 384392.

Fiske, S. T. (1995). Social cognition. In A. Tesser (Ed.), Advanced social psychology (pp. 145-194). New York: McGraw-Hill.

Foster, S. J. (2001). Historical empathy in theory and practice: Some final thoughts. In O. L. Davis, E. A. Yeager \& S. J. Foster (Eds.), Historical empathy and perspective taking in the social studies (pp. 167-181). Lanham, MD: Rowman \& Littlefield.

Galinsky, A. D., \& Moskowitz, G. B. (2000). Perspective-taking: Decreasing stereotype expression, stereotype accessibility, and in-group favoritism. Journal of Personality and Social Psychology, 78(4), 708-724.

Graham, T., \& Ickes, W. J. (1997). When women's intuition isn't greater than men's. In W. J. Ickes (Ed.), Empathic accuracy (pp. 117-143). New York: The Guilford Press.

Gustafsson, J. E. (1984). A unifying model for the structure of intellectual abilities. Intelligence, 8(3), 179-203.

Hodges, S. D., \& Wegner, D. M. (1997). Automatic and controlled empathy. In W. J. Ickes (Ed.), Empathic accuracy (pp. 311-340). New York: The Guilford Press. 
Hoffman, M. L. (2000). Empathy and moral development: Implications for caring and justice. New York: Cambridge University Press.

Ickes, W. J. (Ed.). (1997). Empathic accuracy. New York: The Guilford Press.

Ickes, W. J., Stinson, L., Bissonnette, V., \& Garcia, S. (1990). Naturalistic social cognition: Empathic accuracy in mixed-sex dyads. Journal of Personality \& Social Psychology, 59(4), 730-742.

Johnson, D. W. (1975). Cooperativeness and social perspective taking. Journal of Personality and Social Psychology, 31, 241-244.

Jones, E. E., \& Nisbett, R. E. (1971). The actor and the observer: Divergent perceptions of the causes of behavior. In E. E. Jones, D. E. Kanouse, H. H. Kelly, R. E. Nisbett, S. Valins \& B. Weiner (Eds.), Attribution: Perceiving the causes of behavior. (pp. 79-94). Morristown, NJ: General Learning Press.

Kohlberg, L. (1994). Kohlberg's original study of moral development. New York: Garland Publishing, Inc.

Martinez, M. E. (2000). Education as the cultivation of intelligence. Mahwah, N.J.: Lawrence Erlbaum Associates.

Mendoza, R. (1997). Emotional versus situational inductions of empathy: Effects on interpersonal understanding and punitiveness. Unpublished dissertation, Stanford University, Stanford, CA.

Morris, M. W., \& Peng, K. (1994). Culture and cause: American and Chinese attributions for social and physical events. Journal of Personality and Social Psychology, 67(6), 949-971.

Nucci, L. (1989). Challenging conventional wisdom about morality: The domain approach to values education. In L. Nucci (Ed.), Moral development and character education: A dialogue (pp. 183-203). Berkeley: McCutchan Publishing Corporation.

O'Donoghue, T., \& Rabin, M. (2000). Risky behavior among youths: Some issues from behavioral economics. In J. Gruber (Ed.), Risky behavior among youths: An economic analysis (pp. 29-67). Chicago: University of Chicago Press. 
Oswald, P. A. (2002). The interactive effects of affective demeanor, cognitive processes, and perspective-taking focus on helping behavior. Journal of Social Psychology, 142(1), 120-132.

Roeser, R. W., Eccles, J. S., \& Strobel, K. R. (1998). Linking the study of schooling and mental health: Selected issues and empirical illustrations at the level of the individual. Special Issue: Schooling and mental health: Issues, research, and future directions. Educational Psychologist, 33(4), 153-176.

Rokeach, M. (1960). The open and closed mind: Investigations into the nature of belief systems and personality systems. New York: Basic Books.

Rosenbaum, M. E., \& Holtz, R. (1985). The minimal intergroup discrimination effect: Outgroup derogation, not ingroup favoritism. Paper presented at the 93rd annual convention of the American Psychological Association, Los Angeles.

Ross, L., \& Nisbett, R. E. (1991). The person and the situation: Perspectives of social psychology. New York: McGraw-Hill.

Ross, L., Amabile, T. M., \& Steinmetz, J. L. (1977). Social roles, social control, and biases in social-perception processes. Journal of Personality and Social Psychology, 35(7), 485-494.

Sandy, S. V., \& Cochran, K. M. (2000). The development of conflict resolution skills in children: Preschool to adolescence. In M. Deutsch \& P. T. Coleman (Eds.), The handbook of conflict resolution: Theory and practice (pp. 316-342). San Francisco: Jossey-Bass Inc.

Selman, R. L. (1976). Social-cognitive understanding: A guide to educational and clinical practice. In T. Lickona (Ed.), Moral development and behavior (pp. 299-316). New York: Holt, Rinehart, and Winston.

Selman, R. L. (1980). The growth of interpersonal understanding: Developmental and clinical analyses. New York: Academic Press.

Simpson, J. A., Ickes, W., \& Blackstone, T. (1995). When the head protects the heart: Empathic accuracy in dating relationships. Journal of Personality and Social Psychology, 69(4), 629-641. 
Snow, R. E. (1994). Abilities in academic tasks. In R. J. Sternberg \& R. K. Wagner (Eds.), Mind in context: Interactionist perspectives on human intelligence (pp. 337). New York: Cambridge University Press.

Snow, R. E. (1996). Aptitude development and education. Psychology, Public Policy, and Law, 2(3/4), 536-560.

Snow, R. E., Corno, L., \& Jackson, D., III. (1996). Individual differences in affective and conative functions. In D. C. Berliner \& R. C. Calfee (Eds.), Handbook of educational psychology. (pp. 243-310). New York: Macmillan Library Reference.

Snow, R. E., \& Yalow, E. (1982). Education and intelligence. In R. J. Sternberg (Ed.), Handbook of human intelligence (pp. 493-585). New York: Cambridge University Press.

Stinson, L., \& Ickes, W. (1992). Empathic accuracy in the interactions of male friends versus male strangers. Journal of Personality and Social Psychology, 62(5), 787797.

Taylor, S. E., \& Fiske, S. T. (1975). Point of view and perceptions of causality. Journal of Personality and Social Psychology, 32(3), 439-445.

Wegner, D. M. (1994). Ironic processes of mental control. Psychological Review, 101(1), 34-52. 
Table I

Personal Characteristics and their Expected Impact on SPT Propensity and Ability:

\begin{tabular}{|c|c|c|c|c|c|c|}
\hline DOMAIN & ELEMENT & \multicolumn{3}{|c|}{ CONTINUUM } & \multicolumn{2}{|c|}{ IMPACT ON SPT } \\
\hline & & & & & Propensity & Ability \\
\hline \multirow[t]{2}{*}{$\begin{array}{l}\text { Commitment } \\
\text { Pathway }\end{array}$} & $\begin{array}{l}\text { Motivation: the more motivated people are } \\
\text { to take perspective, the more frequently } \\
\text { and accurately they should take perspective }\end{array}$ & Low & & High & $\uparrow$ & $\uparrow$ \\
\hline & $\begin{array}{l}\text { Emotion Regulation: the more effectively } \\
\text { people can regulate their emotions, the } \\
\text { more frequently and accurately they should } \\
\text { take perspective }\end{array}$ & Unregulated & & $\begin{array}{l}\text { Well- } \\
\text { regulated }\end{array}$ & $\uparrow$ & $\uparrow$ \\
\hline \multirow[t]{3}{*}{$\begin{array}{l}\text { Performance } \\
\text { Pathway }\end{array}$} & $\begin{array}{l}\text { Cognitive ability: the more intelligent } \\
\text { people are, the more accurate they should } \\
\text { take perspective }\end{array}$ & $\begin{array}{l}\text { Low } \\
\text { intelligence }\end{array}$ & & $\begin{array}{l}\text { High } \\
\text { intelligence }\end{array}$ & ? & $\uparrow$ \\
\hline & $\begin{array}{l}\text { Strategy: the more effective the strategies } \\
\text { that people use, the more frequently and } \\
\text { accurately they should take perspective }\end{array}$ & Detrimental & Ineffective & Effective & $\uparrow$ & $\uparrow$ \\
\hline & $\begin{array}{l}\text { Cognitive Style: the more people focus on } \\
\text { the field or situation in perceiving events, } \\
\text { the more frequently and accurately they } \\
\text { should take perspective (up to a point) }\end{array}$ & $\begin{array}{l}\text { Actor- } \\
\text { focused }\end{array}$ & & $\begin{array}{l}\text { Field- } \\
\text { focused }\end{array}$ & $\uparrow$ & $\uparrow$ \\
\hline
\end{tabular}


Table II

Task- and Situation-Level Factors and their Expected Impact on SPT Propensity and Ability:

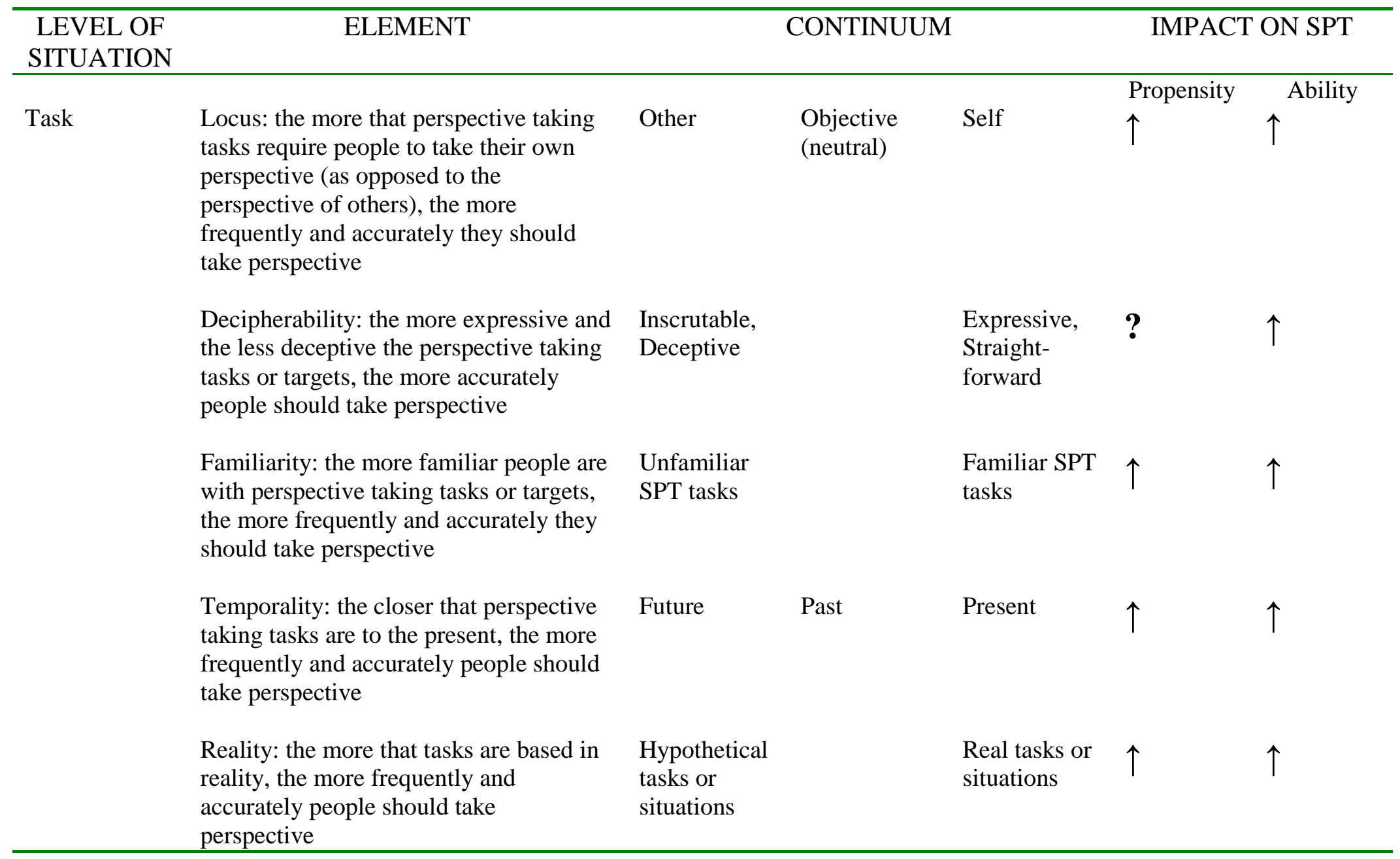




\begin{tabular}{|c|c|c|c|c|c|c|}
\hline & $\begin{array}{l}\text { Duration: the longer people are exposed } \\
\text { to SPT targets, the more accurately they } \\
\text { should take perspective }\end{array}$ & $\begin{array}{l}\text { Brief } \\
\text { exposure }\end{array}$ & & $\begin{array}{l}\text { Extended } \\
\text { exposure }\end{array}$ & $\mathbf{N} / \mathbf{A}$ & $\uparrow$ \\
\hline & $\begin{array}{l}\text { Morality: the more removed a task is } \\
\text { from having a moral dimension to it, the } \\
\text { more accurately people should take } \\
\text { perspective }\end{array}$ & Moral & & Non-moral & $?$ & $\uparrow$ \\
\hline \multirow[t]{2}{*}{ Context } & $\begin{array}{l}\text { Cooperativeness: the more that a } \\
\text { perspective taking task is situated in a } \\
\text { cooperative setting, the more frequently } \\
\text { people should take perspective }\end{array}$ & Competitive & Independent & Cooperative & $\uparrow$ & ? \\
\hline & $\begin{array}{l}\text { Distractions: the fewer the number of } \\
\text { distractions, the smaller the amount of } \\
\text { cognitive load on the perspective takers } \\
\text { and the more frequently and accurately } \\
\text { people should take perspective }\end{array}$ & Many & & Few & $\uparrow$ & $\uparrow$ \\
\hline
\end{tabular}




\section{Figure Caption}

Figure 1. SPT performance as a function of an aptitude complex interacting with a task in a situation

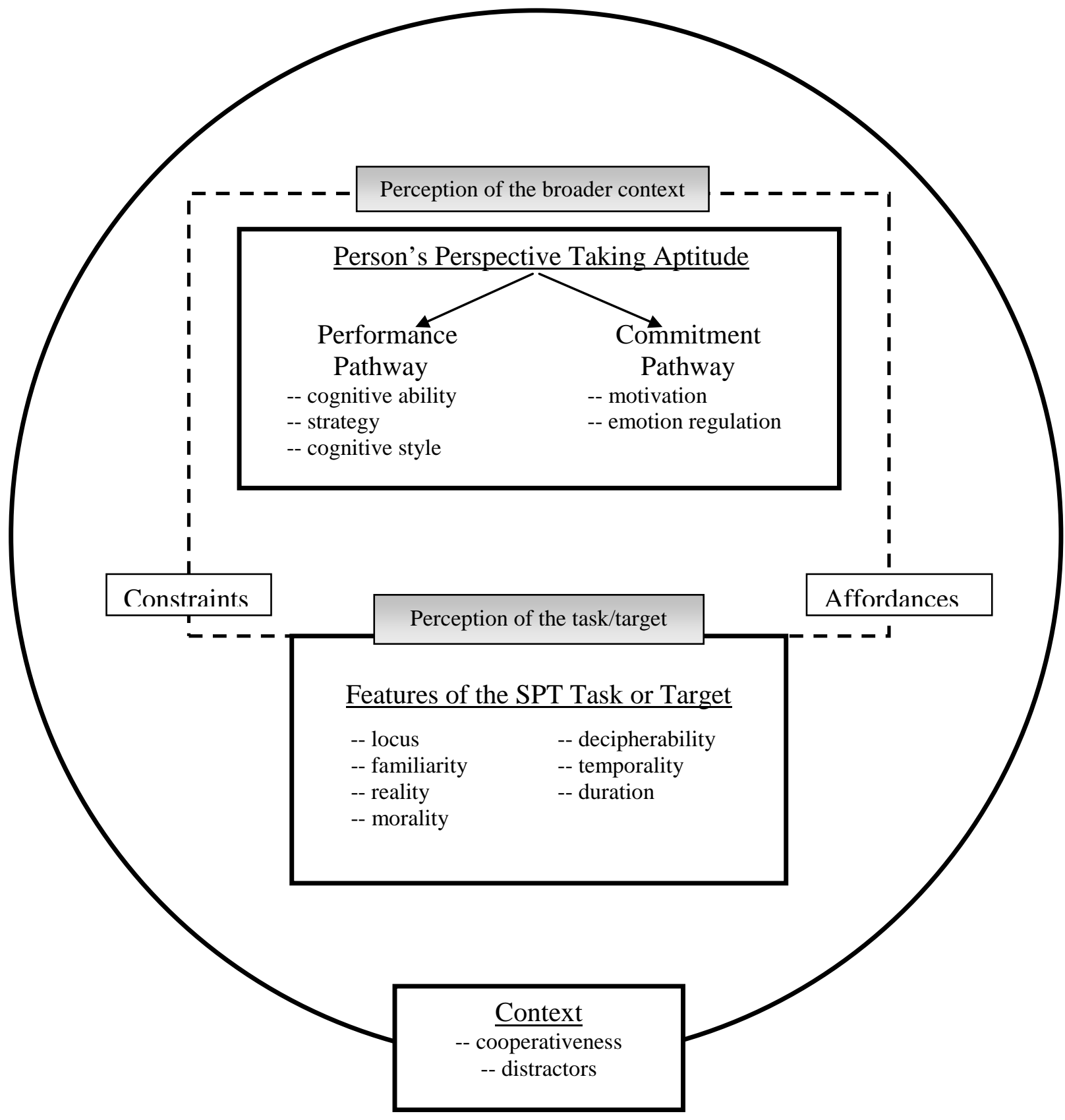

Time 